\title{
COVID-19: Current treatment strategies
}

\author{
Ketki Kalele $^{1 *}$, Rajesh Gondhalekar ${ }^{2}$ \\ ${ }^{\mathbf{1}}$ Assistant Professor, ${ }^{2}$ Dean, HOD, Dept. of Oral Pathology \& Microbiology, V.Y.W.S Dental College \& Hospital, Amravati, \\ Maharashtra, India
}

*Corresponding Author: Ketki Kalele

Email: drketkikalele@gmail.com

Outbreak of Coronavirus pandemic (COVID-19) in Wuhan, China in December 2019 has become a major health emergency of international concern \& millions of people around the globe have been affected by the viral infection. ${ }^{1}$ Looking at the magnitude and severity of the disease, scientist's world wide are tirelessly working for some therapeutic breakthroughs in this arena.

However, till date there has been no sure shot remedy for this highly infective disease. ${ }^{2}$ The novel corona virus (SARS-CoV-2) has crossed the species barriers and has infected humans; which has caused millions of people getting affected by the infection. Multiple factors make this virus difficult to treat and prevent, one of the reason for it is difficulty in tracing the intermediate host in the actual origin of the virus. Understanding of the basic structural binding mechanism of the virus to the host gives the clue for varied range of hosts that the virus may bind to (virus reservoirs). This will further lead us to design countermeasure against the virus. A cryoelectron microscopic study done by Wrapp $\mathrm{D}$ et $\mathrm{al} .{ }^{4}$ has reported that that the binding capacity of SARS-CoV-2 S protein to ACE2 which is human surface receptor is much stronger than that of SARS-CoV, which shows that there are more intermediate hosts for SARS-CoV-2. Liu et al. in their article has stated that From SARS-CoV and MERS-CoV to SARS-CoV-2, all point to bats as the natural host of coronaviruses, but the intermediate hosts for all are different. The article points at snakes, turtles to be more likely \& pangolins or civattes for less likely being the intermediates for SARS-CoV-2. ${ }^{3}$

This article aims to summarize all the drugs and therapies that are presently under consideration and also under trials for the treatment of the disease.

Some of the treatment modalities that are currently in use are-

\section{Chloroquine Phosphate}

Hydrochloroquine which is a potent antimalarial drug has a multidimensional mode of action. The drug has anti parasitic, anti inflammatory and antiviral properties.

In relation to antiviral properties, it is known to bind to ACE-2 spike proteins on SARS-COV-2 and thereby prevent the entry and infection by the virus. It also prevents entry of the virus inside the body by $\mathrm{pH}$ dependent endocytosis. The drug also has optimal safety levels and is shown to be effective at low micromolar concentration. ${ }^{2,5}$

\section{Interferon- $\alpha$}

IFN- $\alpha$ is a broad spectrum antiviral drug for the treatment of hepatitis. The drug has shown good efficacy against SARSCOV-2 in vitro. ${ }^{2,6}$

\section{Lopinavir/Ritonavir}

These are the medications used against Human Immunodeficiency Virus (HIV). These drugs in combination therapy are administered specially for adults \& children over 14 days with HIV. Studies have shown inhibitory effects of these drugs on SARS-COV-2 activity in vitro. $^{2,6}$

\section{Ribavirin}

It is also a broad spectrum antiviral like Lopinavir. Ribavirin in combination with Lopinavir/Ritonavir was shown to lower the risk of acute respiratory distress syndrome (ARDS) development in patients. The combination also has shown to lower the risk of death in the virus infected patients in a study. ${ }^{2,6}$

\section{Arbidol}

An antiviral against Influenza virus has shown to be effective against SARS-COV-2 infection at a concentration of 10-30 micromolar. ${ }^{2,6}$

\section{Favipirvir}

The drug recently got approval (Feb 15/2020) in China for treating novel Influenza virus. The drug is showing efficacy against SARS-COV-2 in some ongoing trials.

It is a RNA polymerase inhibitor. The drug also has potency to block the replication of flavi-, alpha-, filo-, arena-, noro- \& other RNA virus. ${ }^{2,6}$

\section{Remedesivir}

This antiviral drug showed post entry blockage of viral infection with an effective concentration of $50 \%$ of EC $50=$ 0.77 micromolar. ${ }^{2,6}$

\section{Plasma Therapy}

The use of convalescent plasma was recommended as the treatment protocol during outbreaks of Ebola virus in 2014 and Middle East respiratory syndrome coronavirus with convalescent plasma was established in 2015. This therapy when used for other viral infections such as SARS-CoV, H5N1 avian influenza, and H1N1 influenza also showed that transfusion of convalescent plasma was effective. The 
therapy was associated with reduced respiratory tract viral load, serum cytokine response, and mortality. ${ }^{7}$

In the study done by Shen $\mathrm{C}$ et al. on 5 critically ill patients those who were given plasma convalescent therapy, viral load was seen declined within days of treatment with convalescent plasma, and the clinical conditions of these patients improved, as indicated by body temperature reduction, improved $\mathrm{PAO} 2 / \mathrm{FIO} 2$, and chest imaging. Four patients who had been receiving mechanical ventilation and ECMO no longer required respiratory support by 9 days after plasma transfusion. ${ }^{7,8}$

Plasma therapy is specifically useful for patients who are not benefitted by antivirals. In their study, Shen et al reported that SARS-CoV-2 was still detectable in all 5 patents even though antiviral treatment had been given for at least 10 days, although viral load decreased and became undetectable soon after convalescent plasma treatment.

The study opens avenues for the potential of convalescent plasma therapy in patients with SARS-CoV$2 .^{7,8}$

\section{Conclusion}

This article is an attempt to shed some light on the potential therapeutic intervention for the highly infectious SARSCoV-2 amongst all the theories of what is being tried and what is in use and their efficacy levels. It is a glance on the findings of some good clinical trials on certain drugs which can prove to be boon for combating the COVID-19.

\section{Source of Funding}

None.

\section{Conflict of Interest}

None.

\section{References}

1. Salari A, Shirkhoda M. COVID-19 pandemic \& head and neck cancer patients management: The role of virtual multidisciplinary team meetings. Oral Oncol. 2020. doi: 10.1016/j.oraloncology.2020.104693

2. Dong L, Hu S, Gao J. Discovering drugs to treat coronavirus disease 2019 (COVID-19). Drug Discov Ther. 2020;14(1):5860.

3. Liu Z, Xiao X, Wei X. Composition and divergence of coronavirus spike proteins and host ACE2 receptor predicts potential intermediate hosts of SARS-COV-2. J Med Virol. 2020;92:595-601.

4. Wrapp D, Wang N, Corbett KS. Cryo-EM structure of the 2019-nCoV spike in the prefusion conformation. bioRxiv. 2020 https://doi.org/10.1101/2020.02.11.944462

5. Sinha N, Balayla G. Hydroxychloroquine and covid-19. Postgrad Med J. 2020;0:1-6. doi:10.1136/postgradmedj-2020137785.

6. Stockman LJ, Bellamy R, Garner P. SARS: Systematic review of treatment effects. PLoS Med. 2006;3:e343.

7. Chen L, Xiong J, Bao L, Shi Y. Convalescent plasma as a potential therapy for COVID-19. Lancet Infect Dis. 2020;S1473-3099(20)30141-9.

8. Shen C, Wang Z, Zhao F. Treatment of 5 critically ill patients with COVID-19 with convalescent plasma. JAMA. 2020:E1E8.

How to cite this article: Kalele $\mathrm{K}$, Gondhalekar $\mathrm{R}$. COVID-19: Current treatment strategies. J Oral Med, Oral Surg, Oral Pathol, Oral Radiol 2020;6(1):1-5. 